Article

\title{
Dimensionless Study of Double Lungs on Secretion Clearance of a Pressure-Controlled Mechanical Ventilation System
}

\author{
Dongkai Shen ${ }^{1,2}$, Qian Zhang ${ }^{1}$ and Yixuan Wang ${ }^{1, *}$ (D) \\ 1 School of Automation Science and Electrical Engineering, Beihang University, Beijing 100191, China; \\ shen_dk@buaa.edu.cn (D.S.); zhangqian922@buaa.edu.cn (Q.Z.) \\ 2 The State Key Laboratory of Fluid Power Transmission and Control, Zhejiang University, \\ Hangzhou 310058, China \\ * Correspondence: magic_wyx@163.com
}

Received: 1 May 2018; Accepted: 19 June 2018; Published: 3 July 2018

Featured Application: This paper provides a novel research method for a secretion clearance mechanical ventilation system with double lungs, and it promotes the development of mechanical ventilation technology. It can be used in other mechanical ventilation studies as well as clinical medicine and treatment.

\begin{abstract}
A pressure-controlled mechanical ventilator with an automatic secretion clearance function can improve secretion clearance safely and efficiently. Studies on secretion clearance of pressure-controlled systems can be undertaken via clinical treatment and application. However, these studies are based on a single-lung electric model, neglecting the coupling between two lungs. Furthermore, the research methods are too complex to analyze a multiparameter system. In this paper, to grasp the essence of the human respiratory system, a dimensionless mathematical model of a double-lung mechanical ventilation system with a secretion clearance function was built. An experiment was designed to verify the mathematical model by comparison of dimensionless experimental data and dimensionless simulation data. Finally, the coupling between the two lungs was studied, and an orthogonal experiment was designed to identify the impact of each parameter on the system.
\end{abstract}

Keywords: dimensionless system; mechanical ventilation; secretion clearance; double lungs; pressure-controlled

\section{Introduction}

Mechanical ventilation is an important treatment in an intensive care unit (ICU) which usually helps patients who cannot breathe adequately on their own [1-3]. In recent years, there has been a rapid development of mechanical ventilation systems, and studies of respiratory systems can be referred to as a focus on clinical diagnosis and treatments [4-9].

Because of the establishment of an artificial airway and the use of sedatives and muscle relaxants, patients cannot cough when they are in a coma [10-14]. Due to this, expectoration capacity of ventilated patients will further decline and even be lost [15-17]. Furthermore, secretions deposited in the patient's airway aggravate their hypoxia and carbon dioxide retention [18-20] and may result in bacteria collection, which can cause the occurrence or aggravation of a pulmonary infection, such as ventilator associated pneumonia [21-26]. Therefore, secretion clearance has become an important curing and nursing measure for secretion management, which involves members of the ICU care team such as 
doctors, physiotherapists, respiratory therapists, and speech and language therapists [27-30], and it is worthwhile studying the model with secretion clearance function.

Most of the previously studied systems are complex and changeable, and the influence of individual parameters on the whole system is difficult to analyze. Some dynamic characteristics and properties of the respiratory system cannot be measured directly. For a multiparameter mechanical ventilation system, the research method is important. The dimensionless model can simplify the system to analyze the impact of each parameter on the system.

However, many studies regarding mechanical ventilation systems with secretion clearance function are based on a single lung and electric models [31-33], which are only approximately equivalent to the human respiratory systems. However, these studies are not consistent with the actual situation, and their reliability and applicability are greatly reduced, which may not be useful for clinical practice and treatment. Therefore, the establishment of a mathematical model of the mechanical ventilation pneumatic system with double lungs is helpful for promoting the development of mechanical ventilation system research and can be safely and effectively applied to clinical treatment and research.

In this paper, a dimensionless pneumatic mathematical model of a mechanical ventilation system of double lungs with secretion clearance function was built. An experiment with a ventilator with pressure-controlled ventilation mode has been constructed. After comparing the experimental data with the simulation data, the mathematical model can be verified. Then, we can use the simulation model to get data to analyze the influence of each parameter on the coupling of the two lungs. Finally, the impact of each parameter on the respiratory system is obtained by incorporating the orthogonal experiment data.

\section{Introduction of the Mechanical Ventilation System of Double Lungs}

\subsection{Secretion Clearance Ventilation System with Double Lungs}

Mechanical ventilation technology is developing rapidly. The most widely used is positive pressure mechanical ventilation, which has many different modalities [31-33]. Among them, Pressure-controlled Ventilation (PCV) is a classical ventilation model, which is used for respiratory failure [34,35]. Bi-level Positive Airway Pressure (BIPAP) Controlled Ventilation, which is based on $\mathrm{PCV}$, is popular today. The BIPAP ventilator, which is usually of small size, has advantages of simple and safe operation, flexible operation and reliable curative effect. So in this paper, a BIPAP ventilator is used.

The secretion clearance ventilation system with double lungs can be simplified as Figure 1, which is made of one ventilator with secretion clearance function, three tracts and one respiratory airway tract, and two human lungs. According to the working principle of the system, the whole system can be equivalent to a pneumatic system, as is shown in Figure 2.

The ventilator and the pumping unit can be regarded as a compressor and a vacuum pump. The air resistance of the respiratory system can be expressed with three throttle valves. Two variable volumes can be used as human pair of lungs. The pressure in the system is not more than $40 \mathrm{cmH}_{2} \mathrm{O}$, so the compliance of tracts and airway tract can be neglected $[36,37]$. 


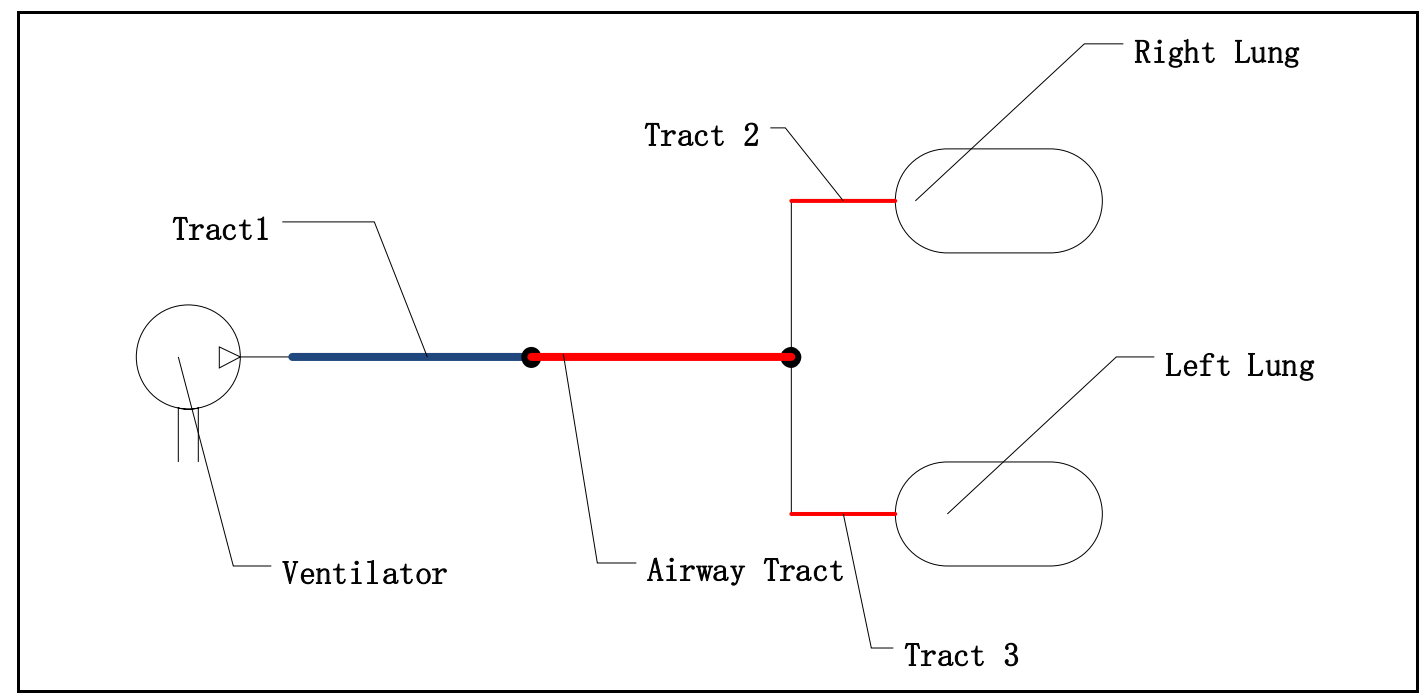

Figure 1. Simplified mechanical ventilation system.

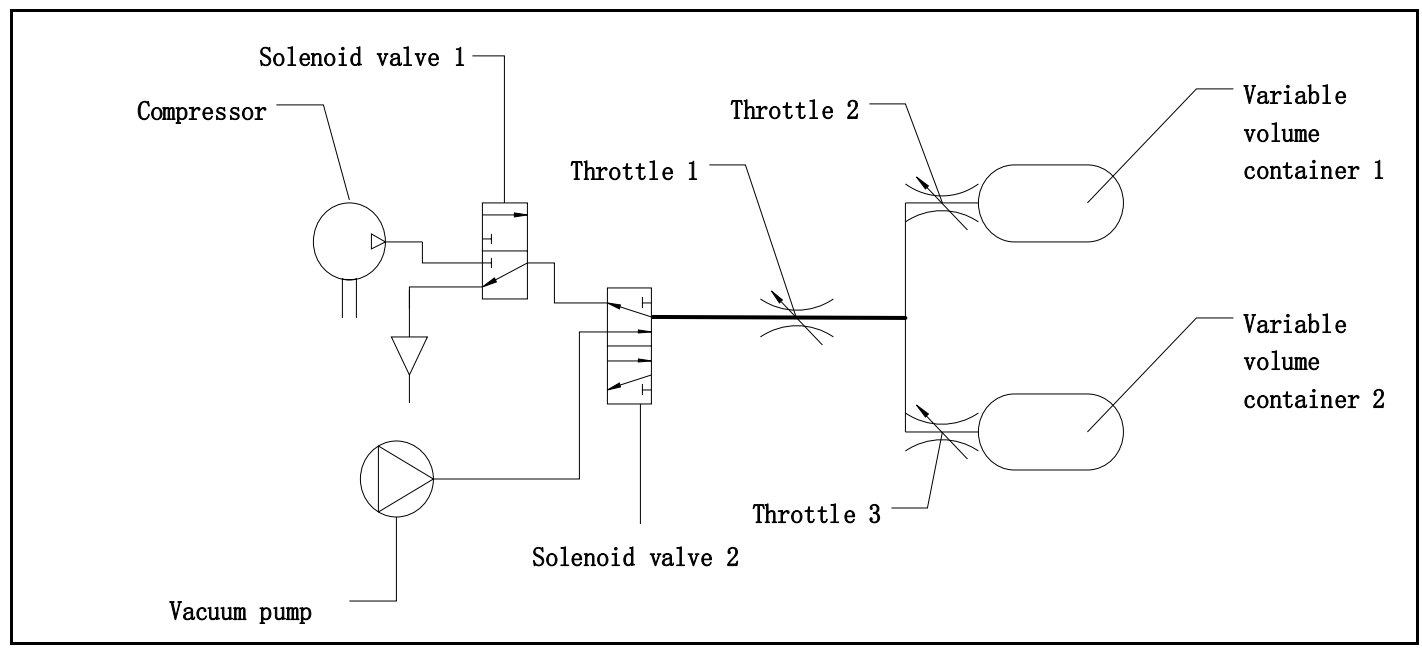

Figure 2. Equivalent pneumatic system.

\subsection{Mathematical Modeling of Mechanical Ventilation System with Double Lungs}

According to the above pneumatic model, we can establish the aerodynamic mathematics equations. However, before that, to make a better study, we put forward the following hypotheses:

(1) The gas in the system is all ideal gas;

(2) There is no air leakage during the working process;

(3) Temperature remains constant during the working process;

(4) Dynamic process of the system is a balanced process;

(5) The state parameters of the air, such as density, specific heat and so on, remain unchanged at any place.

According to the calculation, the pressure range of the system is $2 \mathrm{cmH}_{2} \mathrm{O}$ to $40 \mathrm{cmH}_{2} \mathrm{O}$. Therefore, the value of $p d / p u$ is always bigger than $\mathrm{b}(0.528)$. So the mathematical equations of mechanical ventilation system with double lungs can be got [38-40]: 
2.3. Mass Flow Equation

$$
\begin{gathered}
q_{r}=\frac{n_{i} A_{r} p_{r u} \sqrt{1-b}}{\sqrt{R^{\prime} \theta}} \sqrt{1-\left(\frac{\frac{p_{r d}}{p_{r u}}-b}{1-b}\right)^{2}}, \\
q_{r}=\frac{n_{i} A_{r} p_{r u} \sqrt{1-b}}{\sqrt{R^{\prime} \theta}} \sqrt{1-\left(\frac{\frac{p_{r d}}{p_{r u}}-b}{1-b}\right)^{2},} \\
q_{s}=q_{r}+q_{l},
\end{gathered}
$$

2.4. Volume Flow Equation

$$
\begin{gathered}
Q_{r}=\frac{n_{i} A_{r} p_{r u} \sqrt{1-b}}{\rho_{a} \sqrt{R^{\prime} \theta}} \sqrt{1-\left(\frac{\frac{p_{r d}}{p_{r u}}-b}{1-b}\right)^{2}}, \\
Q_{l}=\frac{n_{i} A_{l} p_{l u} \sqrt{1-b}}{\rho_{a} \sqrt{R^{\prime} \theta}} \sqrt{1-\left(\frac{\frac{p_{l d}}{p_{l u}}-b}{1-b}\right)^{2}}, \\
Q_{s}=Q_{r}+Q_{l},
\end{gathered}
$$

2.5. Pressure Equation

$$
\begin{aligned}
& \frac{d p_{r}}{d t}=\frac{1}{V_{r}} R^{\prime} \theta q_{r}-\frac{m_{r} R^{\prime} \theta}{V_{r}^{2}} \frac{d V}{d t}=\frac{R^{\prime} \theta q_{r} V_{r}}{V_{r}^{2}+C_{r} m_{r} R^{\prime} \theta^{\prime}} \\
& \frac{d p_{l}}{d t}=\frac{1}{V_{l}} R^{\prime} \theta q_{l}-\frac{m_{l} R^{\prime} \theta}{V_{l}^{2}} \frac{d V}{d t}=\frac{R^{\prime} \theta q_{l} V_{l}}{V_{l}^{2}+C_{l} m_{l} R^{\prime} \theta^{\prime}}
\end{aligned}
$$

\subsection{Volume Equation}

The compliance $(C)$ of the two lungs can be described as [41-45]:

$$
\begin{aligned}
& C_{r}=\frac{d V_{r}}{d p_{r}}, \\
& C_{l}=\frac{d V_{l}}{d p_{l}},
\end{aligned}
$$

So the volume of the right lung and left lung can be calculated as [46-50]:

$$
\begin{aligned}
& d \mathrm{~V}_{r}=C_{r} d p_{r}, \\
& d \mathrm{~V}_{l}=C_{l} d p_{l},
\end{aligned}
$$

\subsection{Dimensionless Model of Secretion Clearance Mechanical Ventilation System}

According to the description above, there are many parameters in secretion clearance mechanical ventilation system with double lungs, including the five ventilator parameters IPAP, EPAP, breaths per minute $(\mathrm{BPM})$, inspiratory time $\left(T_{i}\right)$, and rise time of pressure $\left(T_{r i}\right)$. Obviously, it will be complex if we analyze the system directly. Therefore, we can simplify the system, and make the system and the system parameters dimensionless. In this way, the multiparameter mechanical ventilation system will be simple and easy to analyze.

As the research object of this paper is double lungs, the parameters of any lung cannot be regarded as the reference of the whole system. Therefore, the total parameters of the whole respiratory system can be regarded as the reference of the dimensionless system. 
During a respiratory cycle, the tidal volume of the system $\left(V_{t}\right)$ is approximately equal to that of the left lung $\left(V_{l t}\right)$ and the right lung $\left(V_{r t}\right)$. It is the same as the maximal air mass volume $\left(m_{\max }\right)$. The reference air mass flow $\left(q_{\max }\right)$ can take the maximum value of the whole period. When the upstream pressure of the throttle valve reaches IPAP, the downstream pressure reaches EPAP.

$$
\left\{\begin{array}{c}
V_{t}=V_{r t}+V_{l t} \\
m_{\text {max }}=m_{\text {rmax }}+m_{l \text { max }}=\rho_{a} V_{t}=\frac{p_{a} V_{t}}{R^{\prime} \theta} \\
q_{\max }=\frac{A_{e} p_{\text {ipap }} \sqrt{1-b}}{\sqrt{R^{\prime} \theta}} \sqrt{1-\left(\frac{\frac{p_{e p a p}}{p_{\text {ipap }}-b}}{1-b}\right)^{2}}
\end{array}\right.
$$

In addition, the coupling effect between the two lungs of the dimensionless secretion clearance mechanical ventilation system is reflected in the relationship between the dimensionless compliance $\left(C^{*}\right)$ and the resistance $\left(R^{*}\right)$ of the two lungs. According to the structure of the human respiratory system, the lungs are connected in parallel. Compliance $\left(C^{*}\right)$ is in a series relation, and air resistance $\left(R^{*}\right)$ is in a parallel relation. The dimensionless compliance $\left(C^{*}\right)$ and the resistance $\left(R^{*}\right)$ of the two lungs can be obtained based on Kirchhoff's law.

\subsection{Dimensionless Compliance}

$$
\begin{gathered}
C=C_{r}+C_{l}, \\
C^{*}=\frac{C}{C_{0}}=\frac{d V}{d p} \frac{p_{\text {ipap }}}{V_{t}}=\frac{d V^{*}}{d p^{*}}, \\
C_{r}^{*}+C_{l}^{*}=\frac{C_{r}+C_{l}}{C_{0}}=\frac{d V}{d p} \frac{p_{\text {ipap }}}{V_{t}}=1,
\end{gathered}
$$

2.9. Dimensionless Air Resistance

$$
\begin{gathered}
\frac{1}{R}=\frac{1}{R_{r}}+\frac{1}{R_{l}}, \\
R_{r}^{*}=\frac{R_{r}}{R_{0}}=\frac{R_{r}+R_{l}}{R_{l}}, \\
R_{l}^{*}=\frac{R_{l}}{R_{0}}=\frac{R_{r}+R_{l}}{R_{r}}, \\
\frac{1}{R_{r}^{*}}+\frac{1}{R_{l}^{*}}=1,
\end{gathered}
$$

The reference values and the dimensionless variables are shown in Table 1. 
Table 1. The reference values and the dimensionless variables.

\begin{tabular}{|c|c|c|c|}
\hline Variable & \multicolumn{2}{|c|}{ Reference Value } & Dimensionless Variable \\
\hline Air mass & $m_{\max }$ & $\begin{array}{l}\text { Maximal air mass }\left(m_{\max }\right) \\
\text { of the whole system }\end{array}$ & $\begin{array}{l}m_{r}^{*}=\frac{m_{r}}{m_{\max }} \\
m_{l}^{*}=\frac{m_{l}}{m_{\max }}\end{array}$ \\
\hline Pressure & $p_{\text {ipap }}$ & IPAP & $\begin{array}{l}p_{r}^{*}=\frac{p_{r}}{p_{\text {ipap }}} \\
p_{l}^{*}=\frac{p_{l}}{p_{\text {ipap }}}\end{array}$ \\
\hline Air mass flow & $q_{\max }$ & $\begin{array}{l}\text { Maximum air mass flow } \\
\text { through the throttle }\end{array}$ & $\begin{array}{l}q_{r}^{*}=\frac{q_{r}}{q_{\max }} \\
q_{l}^{*}=\frac{q_{l}}{q_{\max }}\end{array}$ \\
\hline Time & $T_{0}=\frac{m_{\max }}{q_{\max }}=\frac{p_{a} V_{t}}{R \theta q_{\max }}$ & $\begin{array}{l}\text { Time to totally exhaust } \\
m_{\max } \text { of air at } q_{\max } \text { of air } \\
\text { mass flow }\end{array}$ & $t^{*}=\frac{t}{T_{0}}$ \\
\hline Volume & $V_{t}$ & Tidal volume & $\begin{array}{l}V_{r}^{*}=\frac{V_{r}}{V_{f}} \\
V_{l}^{*}=\frac{V_{l}}{V_{t}}\end{array}$ \\
\hline Compliance & $C_{0}=\frac{V_{t}}{p_{\text {ipap }}}$ & Ration of $V_{t}$ and $p_{\text {ipap }}$ & $\begin{array}{l}C_{r}^{*}=\frac{C_{r}}{C_{0}} \\
C_{l}^{*}=\frac{C_{l}}{C_{0}}\end{array}$ \\
\hline Air resistance & $R_{0}=\frac{R_{r} R_{l}}{R_{r}+R_{l}}$ & $\begin{array}{l}\text { Total air resistance of the } \\
\text { system }\end{array}$ & $\begin{array}{l}R_{r}^{*}=\frac{R_{r}}{R_{0}} \\
R_{l}^{*}=\frac{R_{l}}{R_{0}}\end{array}$ \\
\hline
\end{tabular}

2.10. Dimensionless Flow Equation

$$
\begin{gathered}
q_{r}^{*}=Q_{r a}^{*}=n_{i} A_{r}^{*} p_{r u}^{*} \frac{\sqrt{1-\left(\frac{\frac{p_{r d}^{*}}{p_{r u}^{*}}-b}{1-b}\right)^{2}}}{\sqrt{1-\left(\frac{p_{e p a p}^{*}-b}{1-b}\right)^{2}}}, \\
q_{l}^{*}=Q_{l a}^{*}=n_{i} A_{l}^{*} p_{l u}^{*} \frac{\sqrt{1-\left(\frac{\frac{p_{l d}^{*}}{p_{l u}^{*}}-b}{1-b}\right)^{2}}}{\sqrt{1-\left(\frac{p_{e p a p}^{*}-b}{1-b}\right)^{2}}},
\end{gathered}
$$

As the equivalent effective area $A_{r}$ and $A_{l}$ is the same as $A_{e}$, Equations (18) and (19) can be rewritten as:

$$
\begin{aligned}
& q_{r}^{*}=n_{i} p_{r u}^{*} \frac{\sqrt{1-\left(\frac{\frac{p}{r d}_{r u}^{*}-b}{1-b}\right)^{2}}}{\sqrt{1-\left(\frac{p_{e p a p}^{*}-b}{1-b}\right)^{2}}} \\
& q_{l}^{*}=n_{i} p_{l u}^{*} \frac{\sqrt{1-\left(\frac{\frac{p_{l d}^{*}}{p_{l u}^{*}}-b}{1-b}\right)^{2}}}{\sqrt{1-\left(\frac{p_{\text {epap }}^{*}-b}{1-b}\right)^{2}}},
\end{aligned}
$$

\subsection{Dimensionless Pressure Equation}

$$
\begin{aligned}
\frac{d p_{r}^{*}}{d t^{*}} & =\frac{T_{0}}{p_{\text {ipap }}} \frac{R \theta q_{r}}{V_{r}+C_{r} p_{r}}=\frac{1}{p_{\text {ipap }}} \frac{p_{a} V_{r t}}{R \theta q_{\text {max }}} \frac{R \theta q_{r}}{V_{r}+C_{r} p_{r}}=\frac{p_{a}^{*} q_{r}^{*}}{V_{r}^{*}+C_{r}^{*} p_{r}^{*}}, \\
\frac{d p_{l}^{*}}{d t^{*}} & =\frac{T_{0}}{p_{\text {ipap }}} \frac{R \theta q_{l}}{V_{l}+C_{l} p_{l}}=\frac{1}{p_{\text {ipap }}} \frac{p_{a} V_{l t}}{R \theta q_{\text {max }}} \frac{R \theta q_{l}}{V_{l}+C_{l} p_{l}}=\frac{p_{a}^{*} q_{l}^{*}}{V_{l}^{*}+C_{l}^{*} p_{l}^{*}},
\end{aligned}
$$

Please note that $p_{a}^{*}$ is dimensionless atmospheric pressure. 
2.12. Dimensionless Volume Equation

$$
\begin{aligned}
& d V_{r}^{*}=C_{r}^{*} d p_{r}^{*}, \\
& d V_{l}^{*}=C_{l}^{*} d p_{l}^{*},
\end{aligned}
$$

During one respiratory cycle, the tidal volume $\left(V_{t}\right)$ in the system is equal to that of the left lung and $\left(V_{l t}\right)$ the right lung $\left(V_{r t}\right)$. So the following equations can be obtained:

$$
V_{r t}^{*}+V_{l t}^{*}=\frac{V_{r t}}{V_{t}}+\frac{V_{l t}}{V_{t}}=1
$$

\subsection{Dimensionless Peak Suction Flow}

The same goes to peak suction flow. In one respiration cycle, the peak suction flow $\left(q_{p}\right)$ in the system is equal to that of the left lung and $\left(q_{l p}\right)$ the right lung $\left(q_{r p}\right)$.

$$
q_{r p}^{*}+q_{l p}^{*}=\frac{q_{r p}}{q_{p}}+\frac{q_{l p}}{q_{p}}=1
$$

According to the equations above, it is obvious that the mathematical model of dimensionless secretion clearance mechanical ventilation system with double lungs is mainly determined by dimensionless compliance $\left(C^{*}\right)$ and dimensionless air resistance $\left(R^{*}\right)$ When the ventilator parameters are set and fixed.

\section{Simulation and Experimental Study on the Mechanical Ventilation System}

\subsection{Experimental Apparatus}

As is shown in Figure 3, an experiment is constructed to verify the mathematical model. Experimental equipment includes a BIPAP ventilator, a pressure-flow sensor which can measure the pressure and flow with two channels, two lung simulators and some tubes.

The BIPAP ventilator is made by HAMILTON-C2, Hamilton Medical AG, Bonaduz, Switzerland, which can provide different mechanical ventilation modes. In addition, before the starting of the experiment, the parameters of ventilator the parameters of the ventilator have been set already. The basic value of IPAP and EPAP is set to $22 \mathrm{cmH}_{2} \mathrm{O}$ and $4 \mathrm{cmH}_{2} \mathrm{O}$, the dimensionless value is 1 and 0.9829 . The basic value of $T_{i}$ and $T_{r}$ is set to $1 \mathrm{~s}$ and $0.3 \mathrm{~s}$, the dimensionless value is 3.1496 and 0.9449 , with the respiratory rate set at 20 cycles per minute.

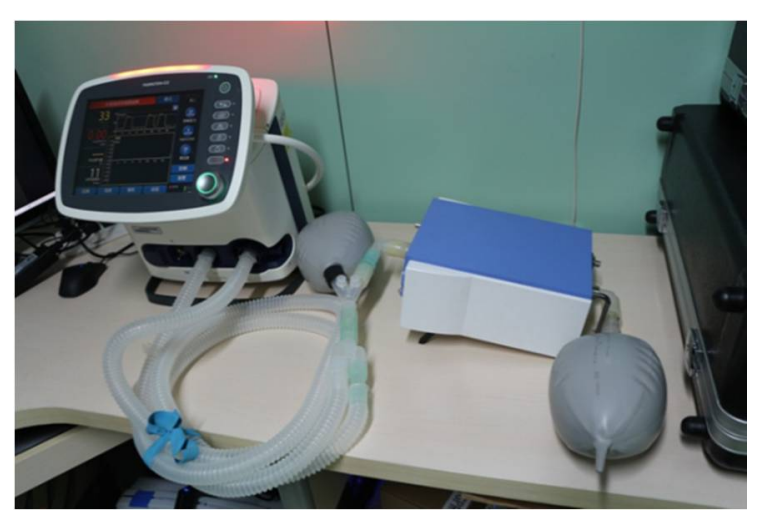

Figure 3. Experiment apparatus. 


\subsection{Simulation of the Ventilation System}

According to the mathematical equations above, the dimensionless simulation model is established by MATLAB/SIMULATION software (MathWorks, Natick, MA, USA). As the BIPAP ventilator does not have the secretion clearance function, the suction pressure of the simulation model is temporarily removed. The parameters of lungs are the same, so the experimental data, which is dimensionless data, can be compared to any one-lung simulation data. The comparison of the dimensionless pressure and flow curve of the experiment between that of the dimensionless simulation are shown in Figures 4 and 5.

\subsection{Analysis and Discussions}

The following conclusions can be drawn from Figures 4 and 5:

(1) The simulation curve is consistent with the experimental curve.

(2) The radian of the pressure experiment curve is greater than that of the pressure simulation curve, and the slope of pressure simulation curve is larger. The reason is that there is a delay in the response time.

(3) The maximum and minimum of simulation curve and experiment curve are the same. The maximum of dimensionless pressure is about 1, which is dimensionless IPAP. In addition, the minimum is about 1 , which is dimensionless EPAP. The experimental parameters of ventilator settings agree with the experimental curves. Therefore the experimental data is safe and reliable.

The experimental design is correct because the resultant in experimental data is reliable.

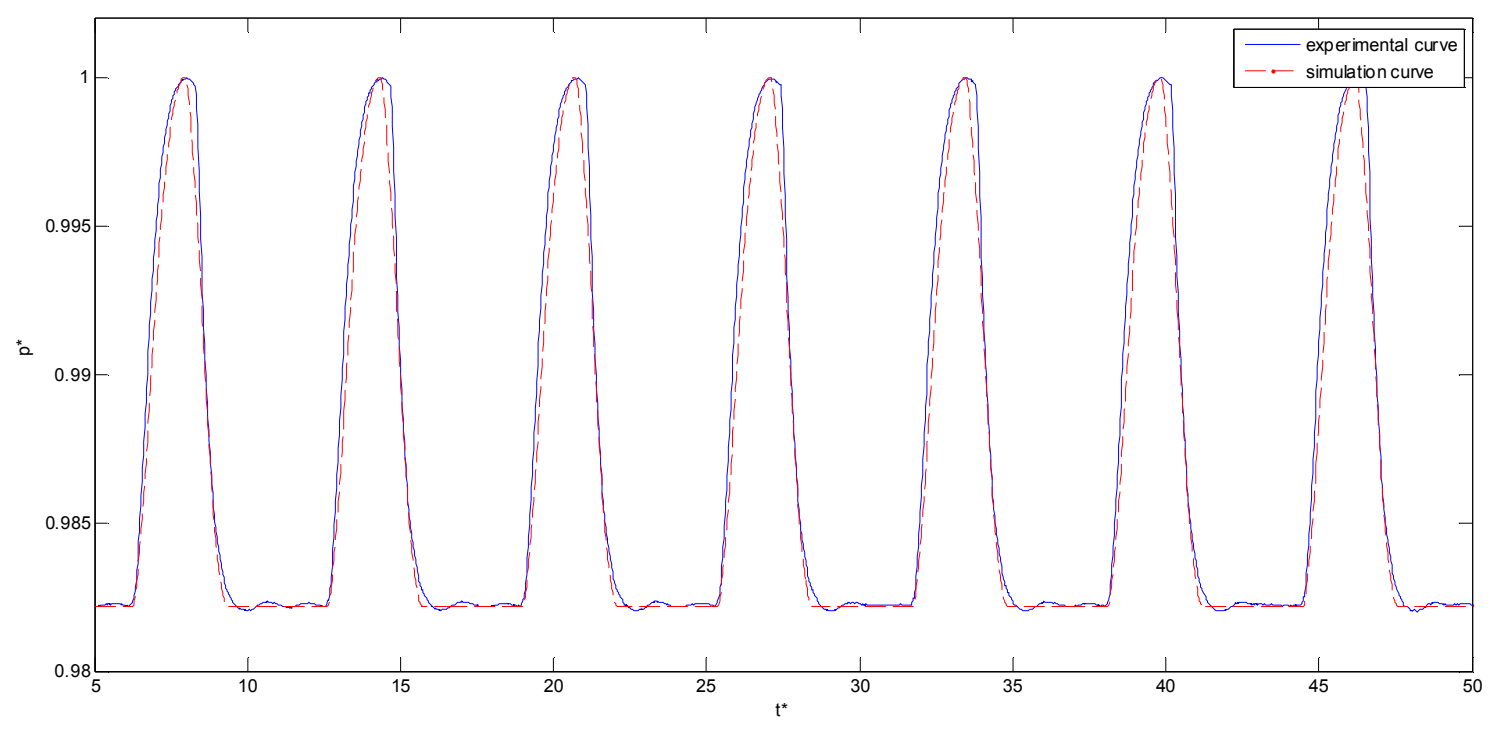

Figure 4. Curve of dimensionless pressure of one lung. 


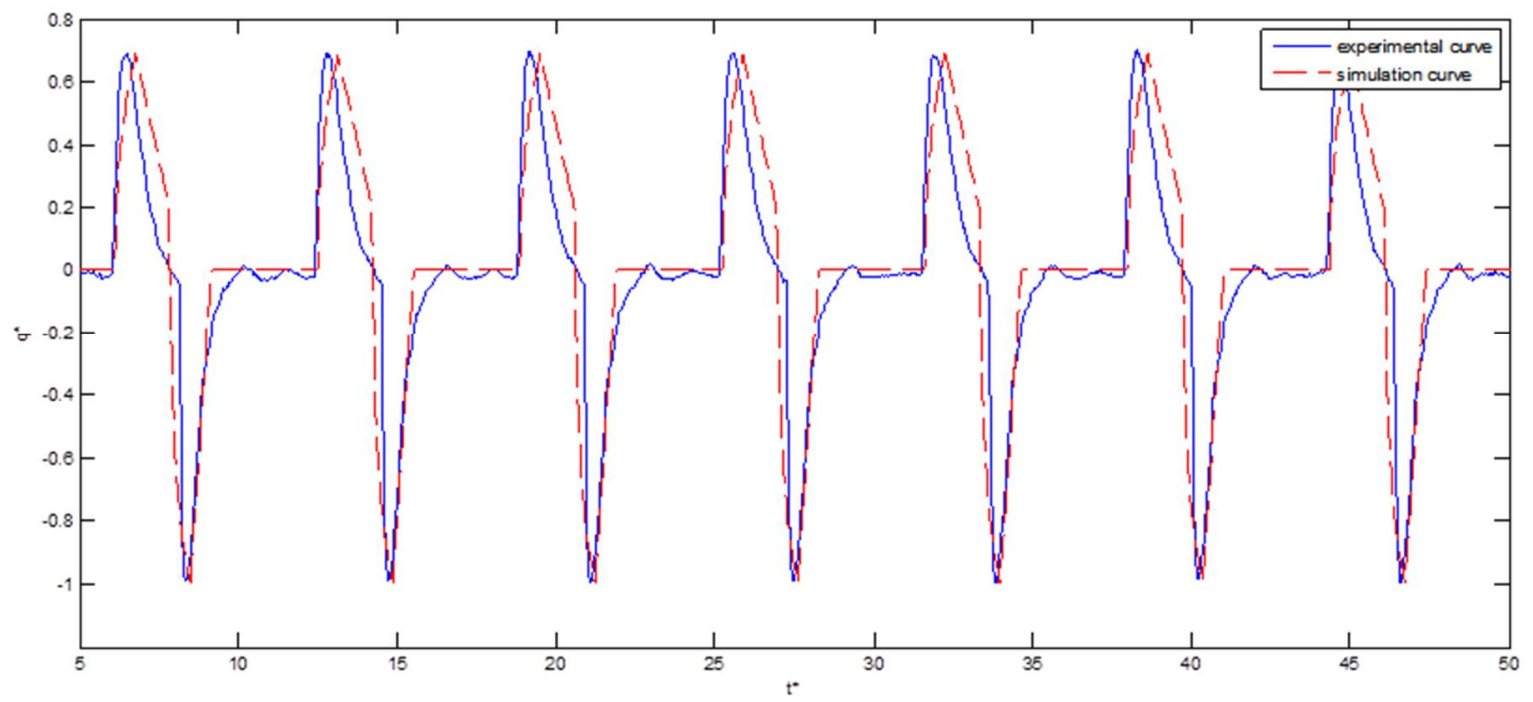

Figure 5. Curve of dimensionless flow in one lung.

\section{Working Characteristics of the Secretion Clearance Ventilation System with Double Lungs}

Studies on system working characteristics are always based on the key parameters [51-54]. In this paper, the study method is basically the same with that.

\subsection{Influence of Dimensionless Compliance and Dimensionless Air Resistance on Secretion Clearance Ventilation System}

According to the description of the mathematical model, dimensionless compliance $\left(C^{*}\right)$ and dimensionless air resistance $\left(R^{*}\right)$ play an important role in the ventilation system. In addition, the coupling between the two lungs is reflected in $C^{*}$ and $R^{*}$, which is based on Equations (13) and (17). When we change the $C^{*}$ or $R^{*}$ of one of the lungs, the $C^{*}$ or $R^{*}$ of the other lung will also be changed. Under normal conditions, the basic values of $C$ of both lungs are set to $10 \mathrm{~mL} / \mathrm{cmH}_{2} \mathrm{O}$, and the basic values of $R$ are set to $6 \mathrm{cmH}_{2} \mathrm{O} / \mathrm{L} / \mathrm{s}$. Only in this way, the maximum value of lung pressure can just reach IPAP 3839. At this point, $C_{r}{ }^{*}$ and $C_{l}{ }^{*}$ are $0.5, R_{r}{ }^{*}$ and $R_{l}{ }^{*}$ are 2.0. The comparison curves between normal state and secretion clearance state are shown in Figure 6.
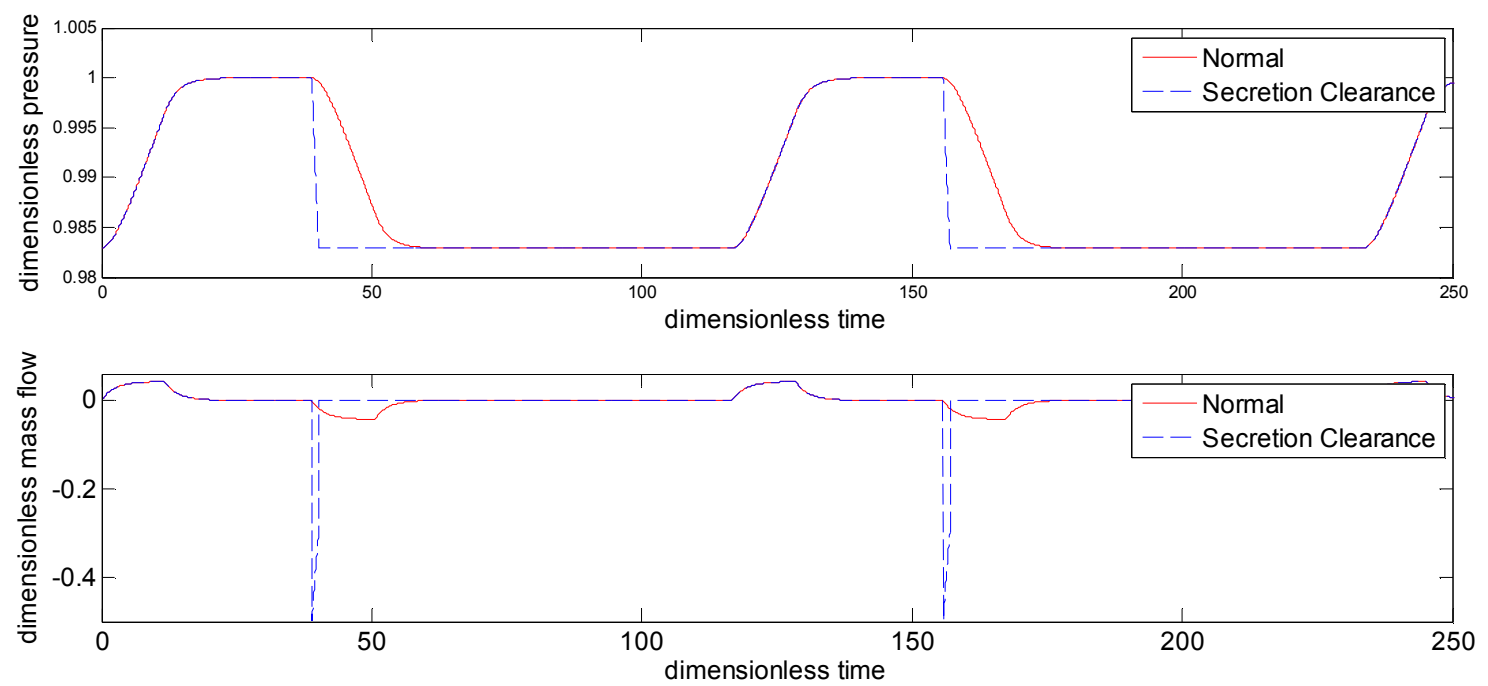

Figure 6. Comparison between normal operation and the secretion clearance function. 
In Figure 6, secretion clearance curve is nearly vertical descent and rise during the expiration process, and the curve of normal is slowly changing. In addition, the time of gas retention in the lung during the secretion clearance state is less than that in the normal state.

\subsection{Influence of Dimensionless Compliance on Secretion Clearance Ventilation System with Double Lungs}

When the value of right lung dimensionless compliance $\left(C_{r}{ }^{*}\right)$ is set to $0.3333,0.5000$, and 0.6000 , the corresponding value for the left lung dimensionless compliance $\left(C_{l}^{*}\right)$ is $0.6667,0.5000$, and 0.4000 . The influence of dimensionless compliance on dimensionless pressure $\left(p^{*}\right)$ and dimensionless air mass flow $\left(q^{*}\right)$ is shown in Figures 7 and 8.

In the right lung, with an increase in $C_{r}{ }^{*}$, the dimensionless time for the respiratory cycle decreases, and the dimensionless time is lower as the dimensionless pressure of the right lung $\left(p_{r}{ }^{*}\right)$ remains equal to the dimensionless IPAP $\left(p_{\text {ipap }}{ }^{*}\right)$. However, for the left lung, the opposite holds. As $C_{l}{ }^{*}$ increases, the dimensionless time of the respiratory cycle increases, and as dimensionless pressure of the left lung $\left(p_{l}^{*}\right)$ approaches $p_{\text {ipap }}{ }^{*}$ the dimensionless time also becomes longer. With an increase in $C_{l}^{*}$, the slope of the $p_{l}{ }^{*}$ curve becomes more gradual. When $C_{r}{ }^{*}>C_{l}^{*}, p_{l}^{*}$ stayed longer in $p_{\text {ipap }}{ }^{*}$ than $p_{r}{ }^{*}$ and stayed in dimensionless EPAP $\left(p_{\text {epap }}{ }^{*}\right)$ for less than $p_{r}^{*}$. When $C_{r}^{*}<C_{l}^{*}$, the state is opposite.

Figure 7 shows that for both lungs, with an increase of $C^{*}$ the peak value of the air mass $\left(q^{*}\right)$ also increases. The dimensionless time becomes longer as negative $q^{*}$ returns to 0 . With the same condition for the two lungs, when $C_{r}^{*}>C_{l}^{*}$, the positive right lung dimensionless air mass flow $\left(q_{r}^{*}\right)$ is higher than the positive left lung dimensionless air mass flow $\left(q_{l}^{*}\right)$, and when $C_{r}{ }^{*}<C_{l}^{*}$, the positive $q_{r}{ }^{*}$ is less than the positive $q_{l}^{*}$.

The influence of $C_{r}^{*}$ on the dimensionless peak suction air flow of right lung $\left(q_{r s}{ }^{*}\right)$, the dimensionless peak suction air flow of left lung $\left(q_{l s}{ }^{*}\right)$ and the dimensionless suction duration $\left(T_{s d}{ }^{*}\right)$ is shown in Figures 9 and 10. These graphs are demarcated by $C_{r}{ }^{*}=C_{l}{ }^{*}=0.5$. In Figure 6, when $C_{r}{ }^{*}<0.5$ (implying $C_{r}{ }^{*}<C_{l}{ }^{*}$ ), the dimensionless peak suction flow $\left(q_{s}^{*}\right)$ of both lungs is about 0.5. It is just a coincidence that the constant value of the left lung compliance is the saturation point of the pressure curve. As the value of IPAP of ventilator output parameter is set to $22 \mathrm{cmH}_{2} \mathrm{O}$, when the basic value of compliance is less than $10 \mathrm{~mL} / \mathrm{cmH}_{2} \mathrm{O}$, the maximum pressure in one lung is equal to IPAP 38, which is a rule about compliance and maximum pulmonary pressure. According to the definition equation of compliance, when the pressure reaches the maximum value and does not change, the maximum flow is saturated. Therefore, the dimensionless peak suction flow $\left(q_{s}^{*}\right)$ of both lungs is approximately equal to 0.5 .

In Figure 10, the curve first increases and then decreases. This is because the suction duration is dependent on the lung whose compliance is less. When $C_{r}>C_{l}$, the suction duration is determined by the left lung. The basic value of the left lung compliance is maintained at $10 \mathrm{~mL} / \mathrm{cmH}_{2} \mathrm{O}$ so the suction duration remains unchanged. However the time reference $\left(T_{0}\right)$ increases with the increase of the dimensionless compliance of the right lung $\left(C_{r}^{*}\right)$, so the second part of the curve shows a decline. 

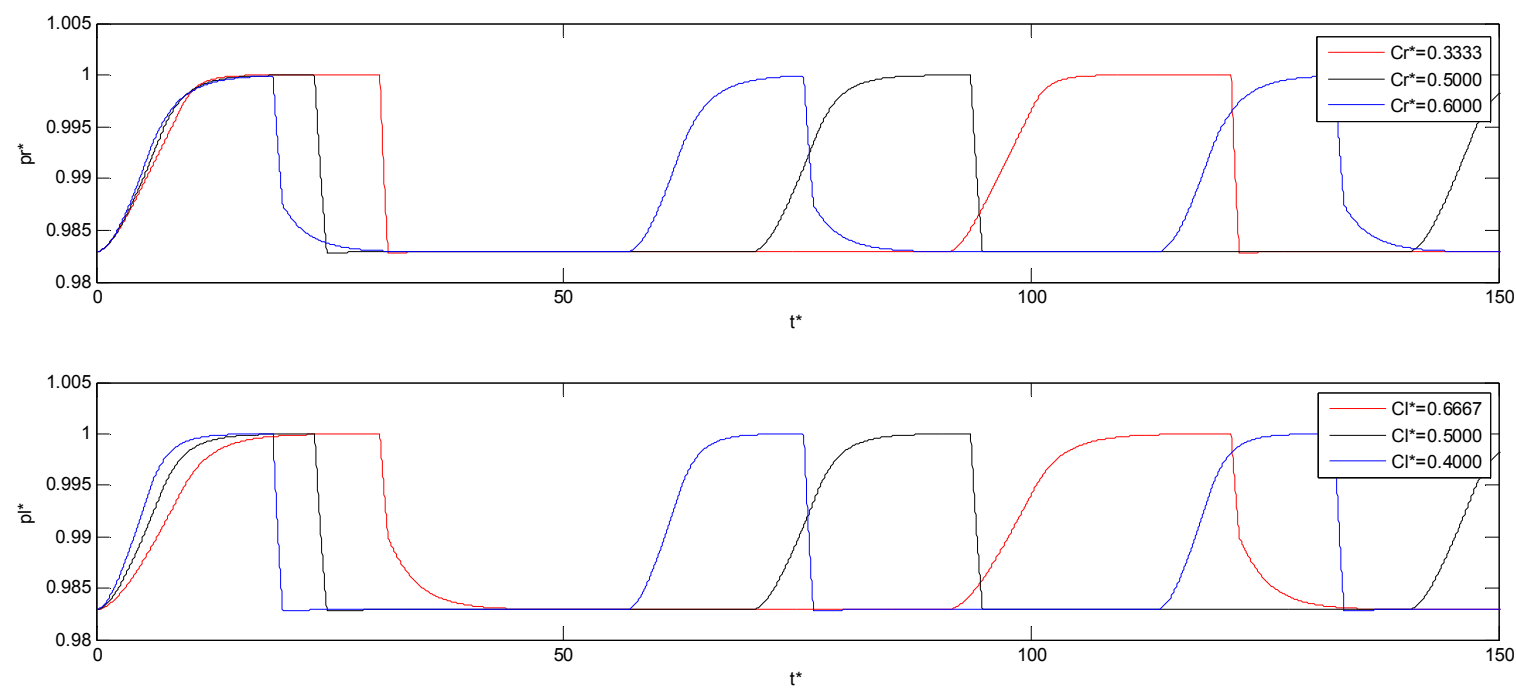

Figure 7. Influence of dimensionless compliance on dimensionless pressure of two lungs.
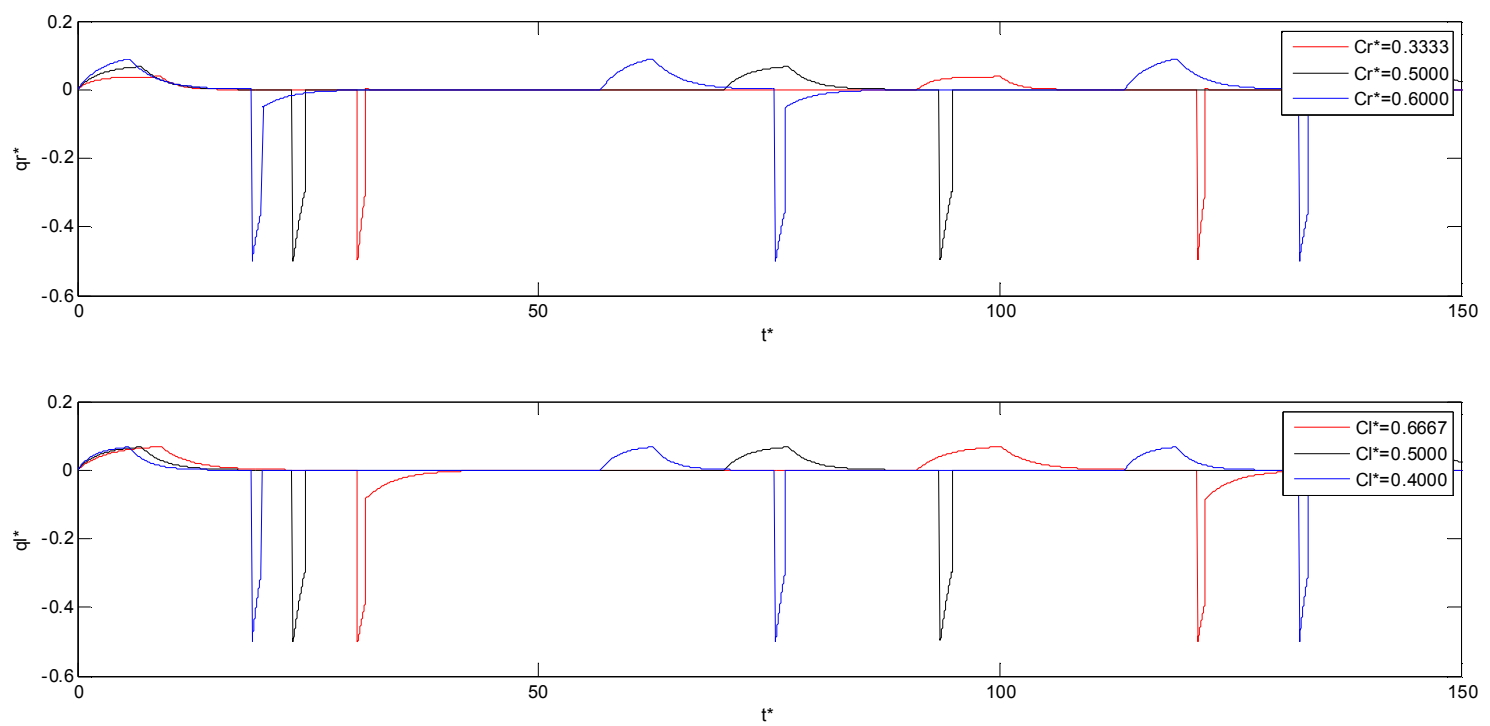

Figure 8. Influence of dimensionless compliance on dimensionless air mass flow of two lungs.

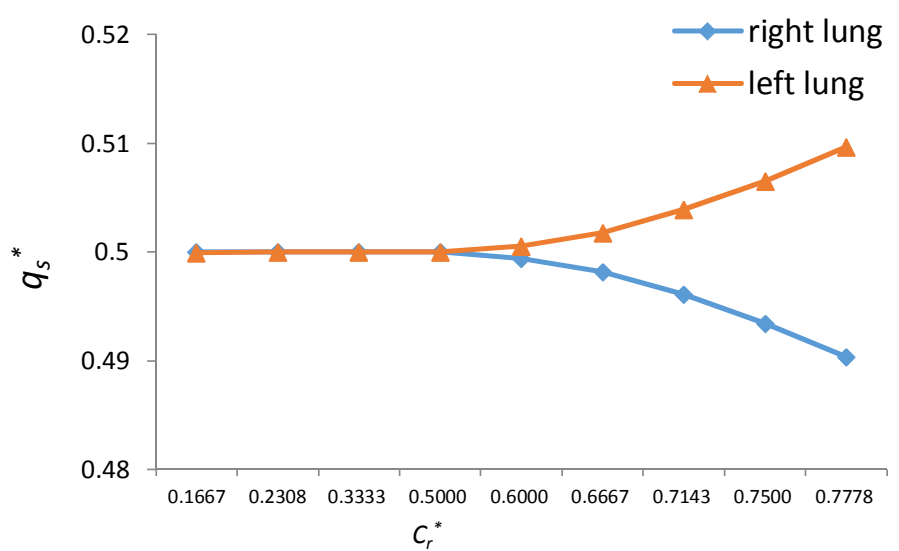

Figure 9. Influence of right lung dimensionless compliance on dimensionless peak suction flow. 


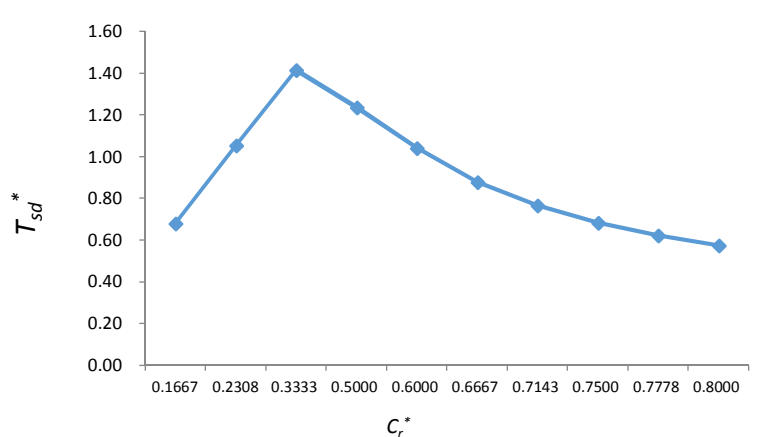

Figure 10. Influence of right lung dimensionless compliance on dimensionless suction duration.

\subsection{Influence of Dimensionless Air Resistance on Secretion Clearance Ventilation System with Double Lungs}

According to Equation (17), when the value of right lung dimensionless air resistance $\left(R_{r}^{*}\right)$ is set to $1.6667,2.0000$ and 2.3333 , the value of left lung dimensionless air resistance $\left(R_{l}{ }^{*}\right)$ is $2.50,2.00$ and 1.75 . The influence of dimensionless air resistance $\left(R^{*}\right)$ on dimensionless pressure $\left(p^{*}\right)$ and dimensionless air mass flow $\left(q^{*}\right)$ are shown in Figures 11 and 12 .

For right lung, when $R_{r}^{*}$ is bigger, the dimensionless time of respiratory cycle is longer. However, it is opposite for left lung. For the same condition in the two lungs, when $R_{r}{ }^{*}>R_{l}{ }^{*}$, the value of dimensionless pressure of right lung $\left(p_{r}^{*}\right)$ arrival dimensionless EPAP $\left(p_{\text {epap }}{ }^{*}\right)$ later than dimensionless pressure of left lung $\left(p_{l}^{*}\right)$, dimensionless suction flow from the right lung is less than that from the left lung. When $R_{r}{ }^{*}<R_{l}{ }^{*}$, the value of $p_{l}{ }^{*}$ reaches $p_{\text {epap }}{ }^{*}$ later than $p_{r}{ }^{*}$, dimensionless suction flow from the right lung is more than that from the left lung.

As is shown in Figure 13, when the $R_{r}{ }^{*}$ rises, the dimensionless peak suction flow of right lung $\left(q_{r s}{ }^{*}\right)$ reduces and the dimensionless peak suction flow of left lung $\left(q_{l s}{ }^{*}\right)$ increases. When $R_{r}{ }^{*}$ rises, $R_{l}{ }^{*}$ decreases. That is to say, the dimensionless peak suction flow $\left(q^{*}\right)$ decreases with the increase of $R^{*}$. The slope of the two curves is different.

From Figure 14, the curve of dimensionless suction duration $\left(T_{s d}{ }^{*}\right)$ increases with the rise of $R_{r}{ }^{*}$, until $R_{r}{ }^{*}$ reaches 2.0, which means $R_{r}{ }^{*}=R_{l}{ }^{*}$. When $R_{r}{ }^{*}>R_{l}{ }^{*}$, the curve of $T_{s d}{ }^{*}$ decreases with the rise of $R_{r}{ }^{*}$. The suction duration is determined by the lung whose air resistance is less. When $R_{r}^{*}<R_{l}^{*}$, the suction duration stays the same due to the unchanged air resistance of left lung. However, the time reference rises with the increase of dimensionless air resistance of right lung $\left(R_{r}^{*}\right)$. So the second half of the curve is falling.
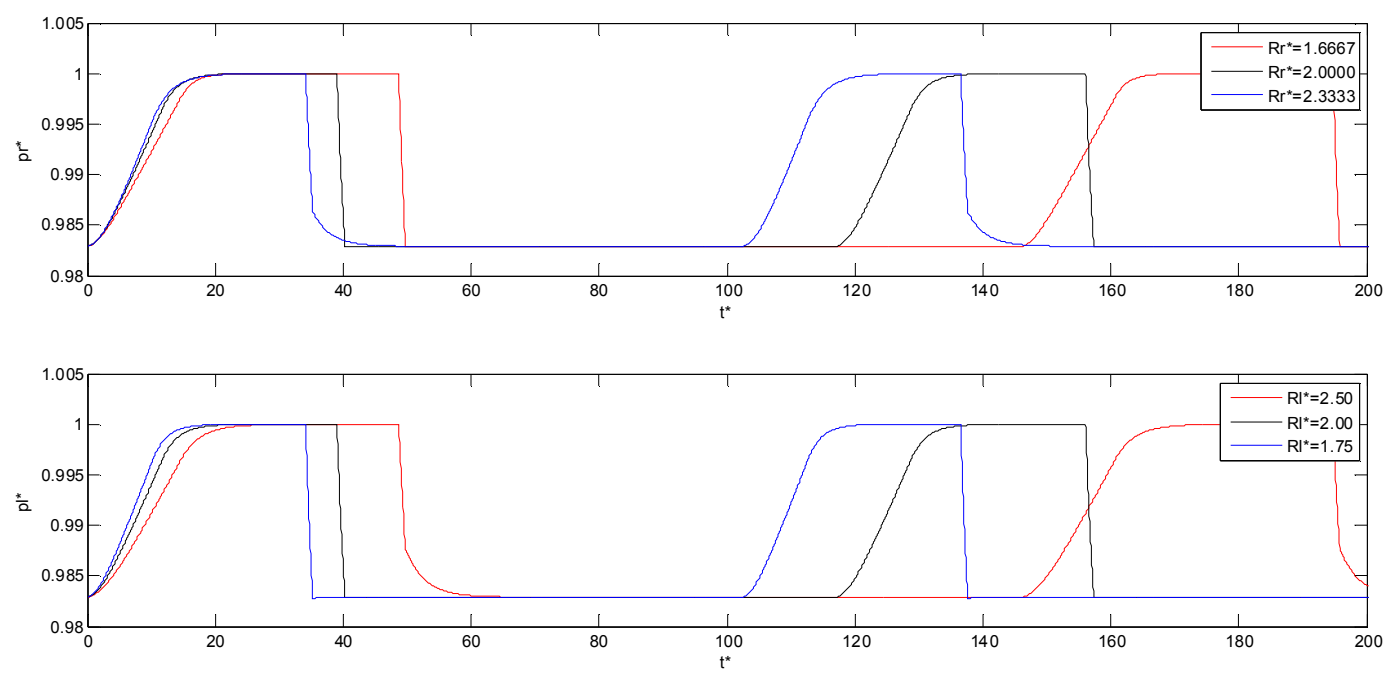

Figure 11. Influence of dimensionless air resistance on dimensionless pressure of two lungs. 

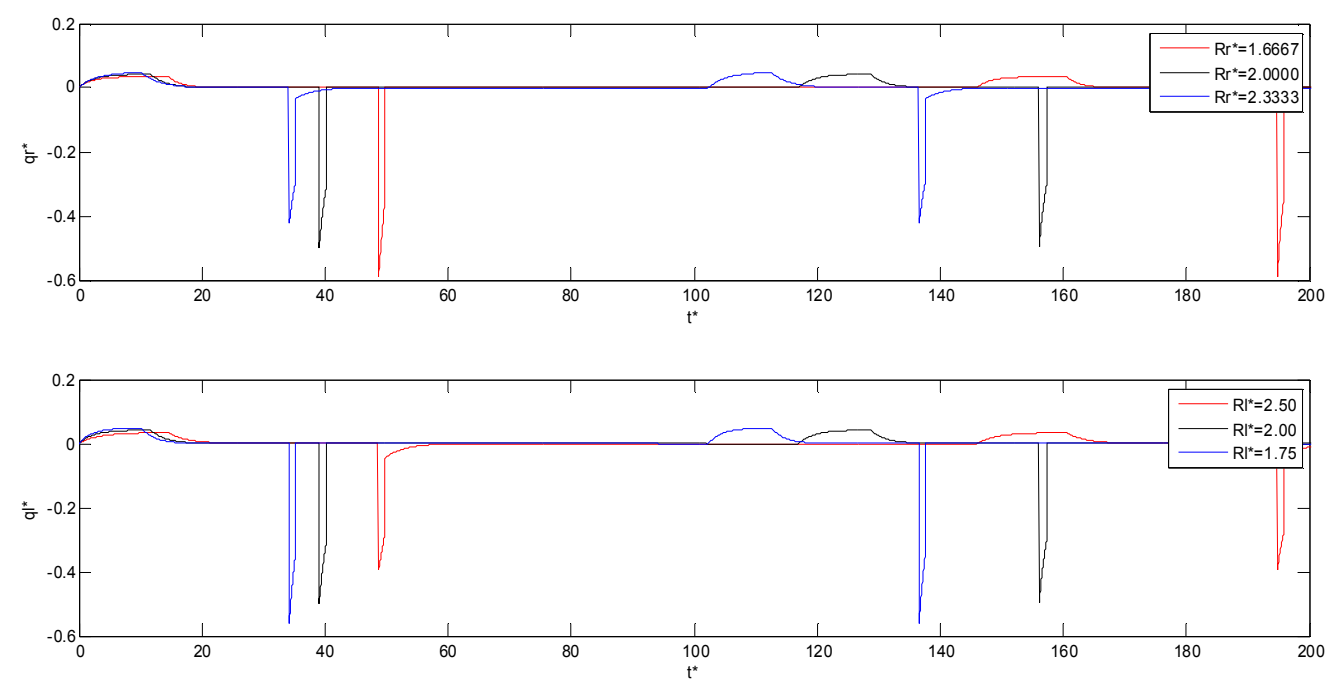

Figure 12. Influence of dimensionless air resistance on dimensionless air mass flow of two lungs.

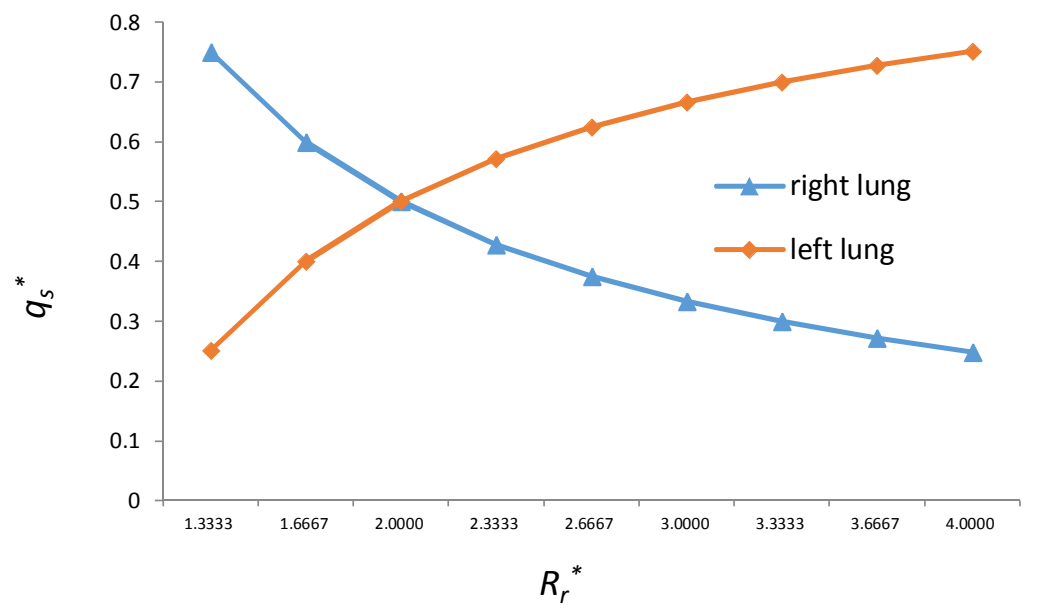

Figure 13. Influence of dimensionless air resistance on dimensionless peak suction flow of two lungs.

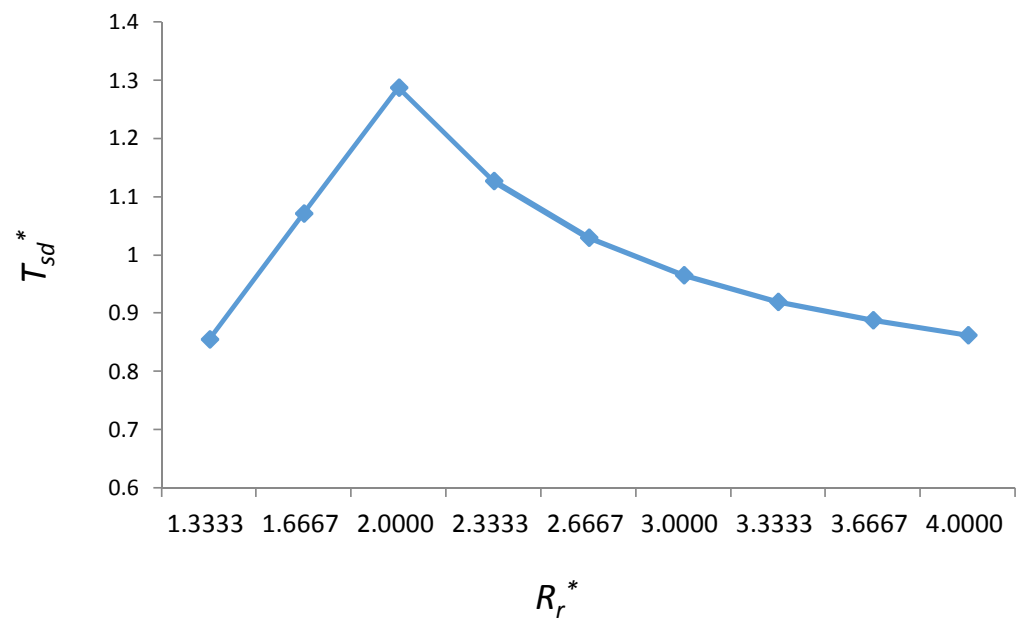

Figure 14. Influence of dimensionless air resistance on dimensionless suction duration. 


\subsection{Orthogonal Experimental}

To study the working characteristics of secretion clearance mechanical ventilation system with double lungs further, an orthogonal experiment is constructed to analyze multi-factor and multi-level, which is representative, and save workload.

According to Equations (13) and (17), change in one of the parameters of one lung affect the parameters of the other lung. So dimensionless compliance of right lung $\left(C_{r}^{*}\right)$ and dimensionless air resistance of right lung $\left(R_{r}^{*}\right)$ was taken to be two of the orthogonal experimental factors. The other factors are dimensionless EPAP $\left(p_{\text {epap }}{ }^{*}\right)$ and dimensionless suction pressure $\left(p_{s}^{*}\right)$. Each parameter takes five different values. Then the parameters value and orthogonal experimental can be designed.

The results of orthogonal experiment can be seen in Figures 15 and 16 After finishing the orthogonal experiment, the standard deviation of each parameter for dimensionless suction duration $\left(T_{s d}{ }^{*}\right)$ and dimensionless peak suction flow $\left(q_{s}^{*}\right)$ were calculated. According to Equation (27), the standard deviation of dimensionless peak suction flow of right lung $\left(q_{r s}{ }^{*}\right)$ are the same with dimensionless peak suction flow of left lung $\left(q_{l s}{ }^{*}\right)$. Therefore just one of the two lungs' standard deviation of $q_{r s}{ }^{*}$ was put down.

It is obvious that, compared with other parameters, dimensionless air resistance $\left(R^{*}\right)$ plays the most important role on both research objects, especially in dimensionless peak suction flow $\left(q_{s}^{*}\right)$. In Figure 15, except dimensionless air resistance $\left(R^{*}\right)$, the dimensionless compliance also has a great influence on dimensionless suction duration.

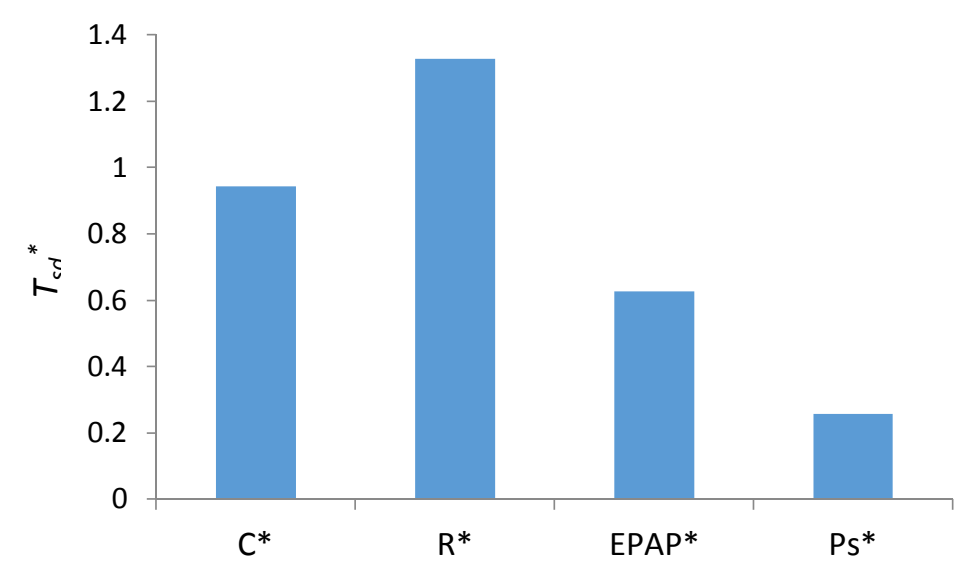

Figure 15. Standard deviation of dimensionless suction duration $\left(T_{s d}{ }^{*}\right)$.

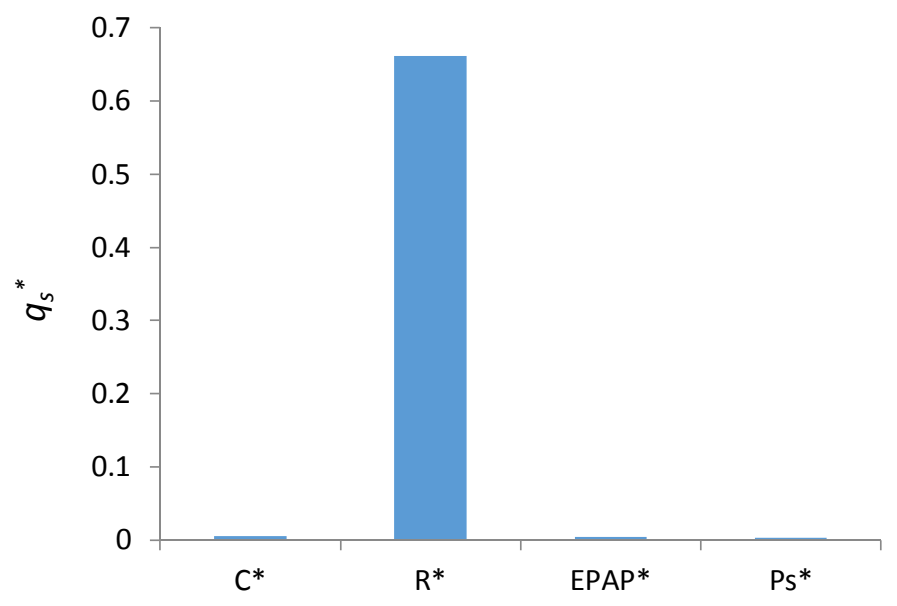

Figure 16. Standard deviation of dimensionless peak suction flow $\left(q_{s}^{*}\right)$. 


\section{Conclusions}

In this paper, firstly a pneumatic model of a mechanical ventilation system of double lungs with secretion clearance function is built. According to that pneumatic model a mathematical dimensionless model is constructed. To verify the mathematical dimensionless model, an experiment with secretion clearance function is designed. Finally, the coupling the working characters of the system and coupling effect between the lungs are obtained by the simulation model and orthogonal experiment.

Therefore, the following conclusions can be drawn:

(1) The output data of the experiment reached the parameters of the ventilator setting. In addition, the simulation curves are consistent with the experimental curves. So the experimental data and simulation data are reliable. In addition, the simulation model can be used in other studies of the respiratory system.

(2) Changes in the dimensionless compliance $\left(C^{*}\right)$ and dimensionless air resistance $\left(R^{*}\right)$ will not only change the system's dimensionless respiratory cycle time, but also change the dimensionless suction duration.

(3) The relationship between dimensionless compliance $\left(C^{*}\right)$ and dimensionless peak suction flow $\left(q_{\mathrm{s}}{ }^{*}\right)$ is not a simple linear relationship. There is a boundary when the dimensionless compliance of the right lung is equal to that of the left lung $\left(C_{\mathrm{r}}{ }^{*}=C_{1}{ }^{*}\right)$. In addition, the relationship between dimensionless air resistance $\left(R^{*}\right)$ and dimensionless peak suction flow $\left(q_{\mathrm{s}}^{*}\right)$ can be regarded as an inversely proportional relationship. They are approximately negatively inversely proportional.

(4) The relationship between dimensionless suction duration $\left(T_{\mathrm{sd}}{ }^{*}\right)$ and dimensionless compliance of right lung $\left(C_{\mathrm{r}}^{*}\right)$ is roughly the same as the relationship between dimensionless suction duration $\left(T_{\mathrm{sd}}{ }^{*}\right)$ and dimensionless air resistance $\left(R_{r}^{*}\right)$. These two curves both raise first and then fall. In general, both the suction duration and time reference increase with the rise of compliance or air resistance. In the second part of these two curves, suction duration stays the same, and time reference increases. Therefore, the dimensionless suction duration of the two curves declines.

(5) Compared with other parameters, dimensionless air resistance $\left(R^{*}\right)$ plays the most important role on both dimensionless suction duration $\left(T_{\mathrm{sd}}{ }^{*}\right)$ and dimensionless peak suction flow $\left(q_{\mathrm{s}}{ }^{*}\right)$. The effect of dimensionless compliance $\left(C^{*}\right)$ on dimensionless suction duration $\left(T_{\mathrm{sd}}{ }^{*}\right)$ is the larger than the other parameters, except for dimensionless air resistance $\left(R^{*}\right)$.

This paper provides a novel research method for a secretion clearance mechanical ventilation system with double lungs, which promotes the development of mechanical ventilation technology and can be used in other mechanical ventilation studies as well as clinical medicine and treatment.

Author Contributions: D.S. and Y.W. conceived and designed the experiments; Q.Z. performed the experiments; Y.W. and Q.Z. analyzed the data, and Q.Z. wrote the paper.

Funding: This work was supported by the National Natural Science Foundation of China (Grant No. 51575020), Open Foundation of the State Key Laboratory of Fluid Power and Mechatronic Systems and the Start-up Research Grant (SRG2016-00083-FHS) at University of Macau.

Conflicts of Interest: The authors declare no conflict of interest.

\section{Nomenclature}

$\begin{array}{ll}A \mathrm{e} & \text { Effective area of throttle }\left(\mathrm{mm}^{2}\right) \\ b & \text { Critical pressure ratio }=0.528 \\ C & \text { Respiratory compliance }\left(\mathrm{L} / \mathrm{cmH}_{2} \mathrm{O}\right) \\ m & \text { Mass of air }(\mathrm{kg}) \\ p & \text { Pressure }(\mathrm{pa}) \\ q & \text { Air mass flow }(\mathrm{kg} / \mathrm{s}) \\ R^{\prime} & \text { Gas constant }=287(\mathrm{~J} /(\mathrm{kg} \cdot \mathrm{K})) \\ R & \text { Respiratory resistance }\left(\mathrm{cmH}_{2} \mathrm{O} / \mathrm{L} / \mathrm{s}\right) \\ \theta & \text { Temperature }(\mathrm{K}) \\ t & \text { Time }(\mathrm{s})\end{array}$




$\begin{array}{ll}V & \text { Volume }\left(\mathrm{m}^{3}\right) \\ \rho & \text { Density }\left(\mathrm{kg} / \mathrm{m}^{3}\right) \\ \mathrm{k} & \text { Specific heat ratio }=1.4 \\ \text { Subscripts } & \\ \mathrm{a} & \text { Atmosphere } \\ \mathrm{e} & \text { Expiration } \\ \text { epap } & \text { Expiatory positive airway pressure } \\ \text { ipap } & \text { Inspiratory positive airway pressure } \\ \mathrm{l} & \text { Left } \\ \mathrm{r} & \text { Right } \\ \mathrm{ri} & \text { Rise } \\ \mathrm{s} & \text { Sum } \\ \mathrm{t} & \text { Tidal } \\ \mathrm{d} & \text { Downstream side } \\ \mathrm{u} & \text { Upstream side } \\ \mathrm{v} & \text { Ventilator or ventilation process } \\ \mathrm{p} & \text { Peak value } \\ \mathrm{s} & \text { suction } \\ \mathrm{d} & \text { duration }\end{array}$

\section{References}

1. Wang, A.; Mahfouf, M.; Mills, G.H.; Panoutsos, G.; Linkens, D.A.; Goode, K.; Kwok, H.F.; Denaï, M. Intelligent model-based advisory system for the management of ventilated intensive care patients. Part II: Advisory system design and evaluation. Comput. Methods Prog. Biomed. 2010, 99, 208-217. [CrossRef] [PubMed]

2. Williams, K.; Hinojosa-Kurtzberg, M.; Parthasarathy, S. Control of Breathing During Mechanical Ventilation: Who Is the Boss? Respir. Care 2010, 56, 127-136. [CrossRef] [PubMed]

3. Shi, Y.; Niu, J.; Cai, M.; Xu, W. Dimensionless Study on Dynamics of Pressure Controlled Mechanical Ventilation System. J. Mech. Sci. Technol. 2015, 29, 431-439. [CrossRef]

4. Ionescu, C.; Derom, E.; de Keyser, R. Assessment of respiratory mechanical properties with constant-phase models in healthy and COPD lungs. Comput. Methods Prog. Biomed. 2010, 97, 78-85. [CrossRef] [PubMed]

5. Chmielecki, J.; Foo, J.; Oxnard, G.R.; Hutchinson, K.; Ohashi, K.; Somwar, R.; Wang, L.; Amato, K.R.; Arcila, M.; Sos, M.L.; et al. Optimization of dosing for EGFRmutant non-small cell lung cancer with evolutionary cancer modeling. Sci. Transl. Med. 2011, 3. [CrossRef] [PubMed]

6. Shi, Y.; Niu, J.; Cao, Z.; Cai, M.; Zhu, J. Working Characteristics of a New Ventilator with Automatic Secretion Clearance Function. Sci. China Technol. Sci. 2015, 58, 1046-1052. [CrossRef]

7. Koc, H.; King, J.; Teschl, G.; Unterkofler, K.; Teschl, S.; Mochalski, P.; Hinterhuber, H.; Amann, A. The role of mathematical modeling in VOC analysis using isoprene as a prototypic example. J. Breath Res. 2011, 5, 037102. [CrossRef] [PubMed]

8. Szaleniec, J.; Składzień, J.; Tadeusiewicz, R.; Oleś, K.; Konior, M.; Przeklasa, R. How can an otolaryngologist benet from arti cial neural networks? Otolaryngol. Pol. 2012, 66, 241-248. [CrossRef] [PubMed]

9. Sturm, R. A computer model for the simulation of ber-cell interaction in the alveolar region of the respiratory tract. Comput. Biol. Med. 2011, 41, 565-573. [CrossRef] [PubMed]

10. Shi, Y.; Zhang, B.; Wang, Z.; Cai, M.; Shen, D. New Advances in Monitoring and Triggering of Mechanical Ventilation. Sci. China Technol. Sci. 2016, 59, 1791-1792. [CrossRef]

11. Katori, H.; Tsukuda, M. Acute epiglottitis: Analysis of factors associated with airway intervention. J. Laryngol. Otol. 2005, 12, 967-972. [CrossRef] [PubMed]

12. Guldfred, L.A.; Lyhne, D.; Becker, B.C. Acute epiglottitis: Epidemiology, clinical presentation, management and outcome. J. Laryngol. Otol. 2008, 122, 818-823. [CrossRef] [PubMed]

13. Gerber, V.; Robinson, N.E. Airway Secretions and Mucociliary Function. Equine Respiratory Medicine and Surgery; Elsevier: Amsterdam, The Netherlands, 2007; pp. 55-69. 
14. Rose, L.; Hanlon, G. Ventilation and Oxygenation Management. ACCCN's Critical Care Nursing; Elsevier: Amsterdam, The Netherlands, 2011; p. 381.

15. Shi, Y.; Niu, J.; Cai, M.; Xu, W. Dimensionless optimization study on a ventilator with secretion clearance function. J. Mech. Med. Biol. 2015, 15, 1550032. [CrossRef]

16. Feltracco, P.; Falasco, G.; Barbieri, S.; Milevoj, M.; Serra, E.; Ori, C. Anesthetic considerations for nontransplant procedures in lung transplant patients. J. Clin. Anesth. 2011, 23, 508-516. [CrossRef] [PubMed]

17. Avinash, S.; Carli, F. The Role of Regional Anaesthesia in Patient Outcome: Thoracic and Abdominal Surgeries. Techniques in Regional Anesthesia and Pain Management; Elsevier: Amsterdam, The Netherlands, 2008; pp. 183-193.

18. Dyhr, T.; Bonde, J.; Larsson, A. Lung recruitment manoeuvres are effective in regaining lung volume and oxygenation after open endotracheal suctioning in acute respiratory distress syndrome. Crit. Care 2003, 7, 55-62. [CrossRef] [PubMed]

19. Maggiore, S.M.; Lellouche, F.; Pigeot, J.; Taille, S.; Deye, N.; Durrmeyer, X.; Richard, J.C.; Mancebo, J.; Lemaire, F.; Brochard, L. Prevention of endotracheal suctioninginduced alveolar derecruitment in acute lung injury. Am. J. Respir. Crit. Care Med. 2003, 167, 1215-1224. [CrossRef] [PubMed]

20. Munnur, U.; Bandi, V.D.; Gropper, M.A. Airway Management and Mechanical Ventilation in Pregnancy, Pulmonary Problems in Pregnancy; Humana Press: New York, NY, USA, 2009; pp. 385-403.

21. Morrissey, B.M. Pathogenesis of bronchiectasis. Clin. Chest Med. 2007, 28, 289-296. [CrossRef] [PubMed]

22. Tsoumakidou, M.; Siafakas, N.M. Novel insights into the aetiology and pathophysiology of increased airway inflammation during COPD exacerbations. Respir. Res. 2006, 7, 1186-1465. [CrossRef] [PubMed]

23. Huh, D.; Fujioka, H.; Tung, Y.-C.; Futai, N.; Paine, R., III; Grotberg, J.B.; Takayama, S. Acoustically detectable cellular-level lung injury induced by fluid mechanical stresses in microfluidic airway systems. Nat. Acad. Sci. 2007, 104, 18886-18891. [CrossRef] [PubMed]

24. Safdar, N.; Crnich, C.J.; Maki, D.G. The pathogenesis of ventilator-associated pneumonia: Its relevance to developing effective strategies for prevention. Respir. Care 2005, 50, 725-741. [PubMed]

25. Branson, R.D. Secretion management in the mechanically ventilated patient. Respir. Care 2007, 52, $1328-1347$. [PubMed]

26. Hess, D.R. Patient positioning and ventilator-associated pneumonia. Respir. Care 2005, 50, 892-899. [PubMed]

27. Redlarski, G.; Jaworski, J. A new approach to modeling of selected human respiratory system diseases, directed to computer simulations. Comput. Biol. Med. 2013, 43, 1606-1613. [CrossRef] [PubMed]

28. Eyles, J.G.; Pimmel, R.L. Estimating respiratory mechanical parameters in parallel compartment models. IEEE Trans. Biomed. Eng. 1981, 28, 313-317. [CrossRef] [PubMed]

29. Diong, B.; Goldman, M.D.; Nazeran, H. Respiratory impedance values in adults are relatively insensitiveto mead model lung compliance and chest wall compliance parameters. In Proceedings of the 26th Southern Biomedical Engineering Conference (SBEC'10), College Park, MD, USA, 30 April-2 May 2010; pp. 201-203.

30. Vassiliou, M.P.; Amygdalou, A.; Psarakis, C.J.; Dalavanga, Y.; Vassiliou, P.M.; Mandragos, K.E.; Constantopoulos, S.H.; Behrakis, P.K. Volume and flow dependence of respiratory mechanics in mechanically ventilated COPD patients. Respir. Physiol. Neurobiol. 2003, 135, 87-96. [CrossRef]

31. Branson, R.D.; Johannigman, J.A.; Campbell, R.S.; Davis, K., Jr. Closed loop mechanical ventilation. Respir. Care 2002, 47, 427-451. [PubMed]

32. Chatburn, R.L.; Mireles-Cabodevila, E. Closed-loop control of mechanical ventilation: Description and classification of targeting schemes. Respir. Care 2011, 56, 85-102. [CrossRef] [PubMed]

33. Tehrani, F.T. Automatic control of mechanical ventilation. Part 2: The existing techniques and future trends. J. Clin. Monit. Comput. 2008, 22, 417-424. [CrossRef] [PubMed]

34. Choi, E.M.; Na, S.; Choi, S.H.; An, J.; Rha, K.H.; Oh, Y.J. Comparison of volume-controlled and pressure-controlled ventilation in steep Trendelenburg position for robot-assisted laparoscopic radical prostatectomy. J. Clin. Anesth. 2011, 23, 183-188. [CrossRef] [PubMed]

35. Karakurt, Z.; Yarkin, T.; Altinöz, H.; Atik Güngör, S.; Adigüzel, N.; Güngör, G.; Demiryontar, D.; Biçakçi, B.; Berk Takir, H.; Unver, E.; et al. Pressure vs. volume control in COPD patients intubated due to ARF: A case-control study. Tuberk uloz ve Toraks 2009, 57, 145-154.

36. Robert, L. Computer control of mechanical ventilation. Respir. Care 2004, 49, 507-515.

37. Borrello, M. Modeling and control of systems for critical care ventilation. In Proceedings of the 2005 American Control Conference, Portland, OR, USA, 8-10 June 2005; pp. 2166-2180. 
38. Shi, Y.; Ren, S.; Cai, M.; Xu, W.; Deng, Q. Pressure Dynamic Characteristics of Pressure Controlled Ventilation System of a Lung Simulator. Comput. Math. Methods Med. 2011, 10, 1155-1164. [CrossRef] [PubMed]

39. Shi, Y.; Cai, M. Working characteristics of two kinds of air driven boosters. Energy Convers. Manag. 2011, 52, 3399-3407. [CrossRef]

40. Liu, Y.; Pei, P. Asymptotic analysis on autoignition and explosion limits of hydrogen-oxygen mixtures in homogeneous systems. Int. J. Hydrogen Energy 2006, 31, 639-647. [CrossRef]

41. Niu, J.; Shi, Y.; Cai, M.; Cao, Z.; Wang, D.; Zhang, Z.; Zhang, D.X. Detection of Sputum by Interpreting the Time-frequency Distribution of Respiratory Sound Signal Using Image Processing Techniques. Bioinformatics 2017. [CrossRef] [PubMed]

42. Niu, J.L.; Shi, Y.; Cao, Z.X.; Cai, M.L.; Chen, W.; Zhu, J.; Xu, W. Study on air flow dynamic characteristic of mechanical ventilation of a lung simulator. Sci. China Technol. Sci. 2017, 60, 1-8. [CrossRef]

43. Ren, S.; Shi, Y.; Cai, M.; Xu, W. Influence of secretion on airflow dynamics of mechanical ventilated respiratory system. IEEE/ACM Trans. Comput. Biol. Bioinform. 2017. [CrossRef] [PubMed]

44. Shi, Y.; Zhang, B.; Cai, M.; Xu, W. Coupling Effect of Double Lungs on a VCV Ventilator with Automatic Secretion Clearance Function. IEEE/ACM Trans. Comput. Biol. Bioinform. 2017. [CrossRef] [PubMed]

45. Shi, Y.; Zhang, B.; Cai, M.; Zhang, D. Numerical Simulation of volume-controlled mechanical ventilated respiratory system with two different lungs. Int. J. Numer. Methods Biomed. Eng. 2016, 33, 2852. [CrossRef] [PubMed]

46. Ren, S.; Cai, M.; Shi, Y.; Xu, W.; Zhang, X.D. Influence of Bronchial Diameter Change on the airflow dynamics Based on a Pressure-controlled Ventilation System. Int. J. Numer. Methods Biomed. Eng. 2017. [CrossRef] [PubMed]

47. Shi, Y.; Niu, J.; Cao, Z.; Cai, M.; Zhu, J.; Xu, W. Online estimation method for respiratory parameters based on a pneumatic model. IEEE/ACM Trans. Comput. Biol. Bioinform. 2016, 13, 939-946. [CrossRef] [PubMed]

48. Diong, B.; Goldman, M.; Nazeran, H. Respiratory impedance values in adults are relatively insensitive to mead model lung compliance and chest wall compliance parameters. Proc. IFMBE 2010, 32, 201-203.

49. Shi, Y.; Ren, S.; Cai, M.; Xu, W. Modelling and simulation of volume controlled mechanical ventilation system. Math. Probl. Eng. 2014, 2014. [CrossRef]

50. Shi, Y.; Ren, S.; Cai, M.; Xu, W. Working characteristics of a mechanical insufflation-exsufflation device. Math. Probl. Eng. 2014, 2014. [CrossRef]

51. Shi, Y.; Wang, Y.; Cai, M.; Zhang, B.; Zhu, J. Study on the Aviation Oxygen Supply System Based on a Mechanical Ventilation Model. Chin. J. Aeronaut. 2017. [CrossRef]

52. Shi, Y.; Wang, Y.; Liang, H.; Cai, M. Power characteristics of a new kind of air-powered vehicle. Int. J. Energy Res. 2016, 40, 1112-1121. [CrossRef]

53. Cai, M.; Wang, Y.; Shi, Y.; Liang, H. Output dynamic control of a late model sustainable energy automobile system with nonlinearity. Adv. Mech. Eng. 2016, 8. [CrossRef]

54. Shi, Y.; Wu, T.; Cai, M.; Wang, Y.; Xu, W. Energy conversion characteristics of a hydropneumatic transformer in a sustainable-energy vehicle. Appl. Energy 2016, 171,77-85. [CrossRef]

(c) 2018 by the authors. Licensee MDPI, Basel, Switzerland. This article is an open access article distributed under the terms and conditions of the Creative Commons Attribution (CC BY) license (http://creativecommons.org/licenses/by/4.0/). 